\title{
Two distinct insulin-related molecules in the guinea pig: immunological and biochemical characterization of insulin-like immunoactivity from extrapancreatic tissues of the guinea pig
}

\author{
J.L. Rosenzweig ${ }^{1}$, D. LeRoith ${ }^{1}$, M. A. Lesniak ${ }^{1}$, C.C. Yip ${ }^{2}$, D. N. Orth ${ }^{3}$, H. R. Nankin ${ }^{4}$, P. Murone ${ }^{4}$, M. Berelowitz ${ }^{5}$, \\ L.A. Frohman ${ }^{5}$, A.S. Liotta ${ }^{6}$, D.T. Krieger ${ }^{6}$ and J. Roth ${ }^{1}$ \\ ${ }^{1}$ Diabetes Branch, National Institutes of Arthritis, Diabetes, Digestive and Kidney Diseases, National Institutes of Health, Bethesda, Maryland, \\ USA, ${ }^{2}$ Banting and Best Department of Medical Research, University of Toronto, Charles H. Best Institute, Toronto, Canada, ${ }^{3}$ Department of \\ Medicine, Vanderbilt University Medical School, Nashville, Tennessee, ${ }^{4}$ Department of Medicine, William Jennings Bryan Dorn Veterans \\ Administration Hospital and University of South Carolina, Columbia, South Carolina, ${ }^{5}$ Department of Medicine, University of Cincinnati, Ohio, \\ and ${ }^{6}$ Department of Medicine, Mt. Sinai School of Medicine, New York, New York, USA
}

\begin{abstract}
Summary. In this study we extracted guinea pig brain and testis with; the extract was adsorbed to and eluted from cartridges (the Sep-Pak C18 procedure). We found this procedure superior for recovering crystalline insulin added to buffers or tissues, and for recovering endogenous insulin from plasma, but inferior for recovery of insulin from tissues. However, we did find 'rat/pork' type-insulin in guinea pig brain and testis $(5-50 \mathrm{pg} / \mathrm{g}$ wet weight tissue). Our results with the Sep-Pak C18 procedures were reproduced by four other laboratories (who found $4-60 \mathrm{pg} / \mathrm{g}$ wet weight of tissue) and simi-
\end{abstract}

lar findings were also obtained by an independent investigator. Thus, we conclude that extrapancreatic tissues of guinea pigs have a second type of insulin-related material that is more typical of other mammalian insulins, but that the amount recovered is dependent upon the extraction procedure utilized.

Key words: Guinea pig, extrapancreatic tissues, insulin-related immunoactivity.
Previously we reported (NIH and Toronto) that guinea pigs have two distinct insulin-related materials [1]. Typical guinea pig pancreatic insulin, which has features that distinguish it from other mammalian insulins, is present in high concentrations in pancreas and blood, and in very modest amounts in extrapancreatic tissues. In addition, material with the immunological properties typical of the mammalian insulins (abbreviated 'rat/ pork'-type insulin) is present in extrapancreatic tissues of the guinea pig. We concluded that these findings provide support for the suggestion that extrapancreatic tissues normally produce small amounts of insulin [1].

Using a different purification technique, one group of workers reported their inability to reproduce the data [2], although the presence of 'rat/pork'-type insulin immunoreactivity in guinea pig brain was recently confirmed [3]. In the present study, we and four collaborative groups (Nashville, Columbia, Cincinnati and New York), using a new purification procedure, have examined extrapancreatic tissues of the guinea pig for the presence of 'rat/pork'-type insulin.

\section{Materials and methods}

\section{Tissues and organs}

Male guinea pigs (NIH stain, $250-500 \mathrm{~g}$ ) were asphyxiated with carbon dioxide. (Studies with 12 Hartley strain guinea pigs gave similar results to NIH strain guinea pigs.) The livers, testes and brains were immediately dissected, frozen on dry ice, and stored at $-70^{\circ} \mathrm{C}$. To avoid exogenous contamination, disposable equipment and new reagents, glassware, and blenders were used for each experiment.

\section{Extraction procedure 1}

Step 1: extraction into acid ethanol. All steps were performed at $4{ }^{\circ} \mathrm{C}$ except where noted otherwise. Frozen tissues were weighed and homogenized in $0.2 \mathrm{~N} \mathrm{HCl}-75 \%$ ethanol $(10 \mathrm{ml} / \mathrm{g}$ of tissue $)$ for $1-2 \mathrm{~min}$ with a Waring blender set at maximum speed. Homogenates were shaken overnight and then centrifuged at $1500 \mathrm{~g}$ for $30 \mathrm{~min}$ and the insoluble material was discarded.

Step 2: evaporation of ethanol. The acid ethanol extracts were concentrated by air evaporation to one-twentieth of the original volume [4] and resuspended in $\left(\mathrm{NH}_{4}\right)_{2} \mathrm{CO}_{3}(0.05 \mathrm{~mol} / \mathrm{l})$.

Step 3: neutralization. The $\mathrm{pH}$ was adjusted to 7-8 with concentrated $\mathrm{NH}_{4} \mathrm{OH}$; undissolved material was removed by centrifugation at $1500 \mathrm{~g}$ for $25 \mathrm{~min}$. Supernatants were frozen on dry ice and lyophilized. (Neither albumin nor ${ }^{125} \mathrm{I}$-insulin were added at any stage).

Step 4: Sephadex $G-50$ gel filtration. The extracts were reconstituted in $\left(\mathrm{NH}_{4}\right)_{2} \mathrm{CO}_{3}(0.05 \mathrm{~mol} / \mathrm{l}, \mathrm{pH} 8.0)$, applied to columns of Sephadex G50 (fine), and eluted in the same buffer. Fractions $(1 \mathrm{ml})$ were collected, lyophilized and the immunoactive insulin content of each fraction measured by radioimmunoassay. Each effluent fraction was lyophilized twice and reconstituted in $1-2 \mathrm{ml}$ distilled water. Samples $(50 \mu \mathrm{l}$ or $100 \mu \mathrm{l}$ ) were assayed in a total volume of $500 \mu \mathrm{l}$. No adjustments for variations in $g$ wet weight, protein concentrations or recoveries between samples were made.

\section{Extraction procedure 2}

Step 1: extraction into acid ethanol. Same as procedure 1, step 1.

Step 2: adsorption onto Sep-Pak cartridges and elution. ODS silica C 18 cartridges (Sep-Pak, Waters Associates, Milford, Mass, USA) were 

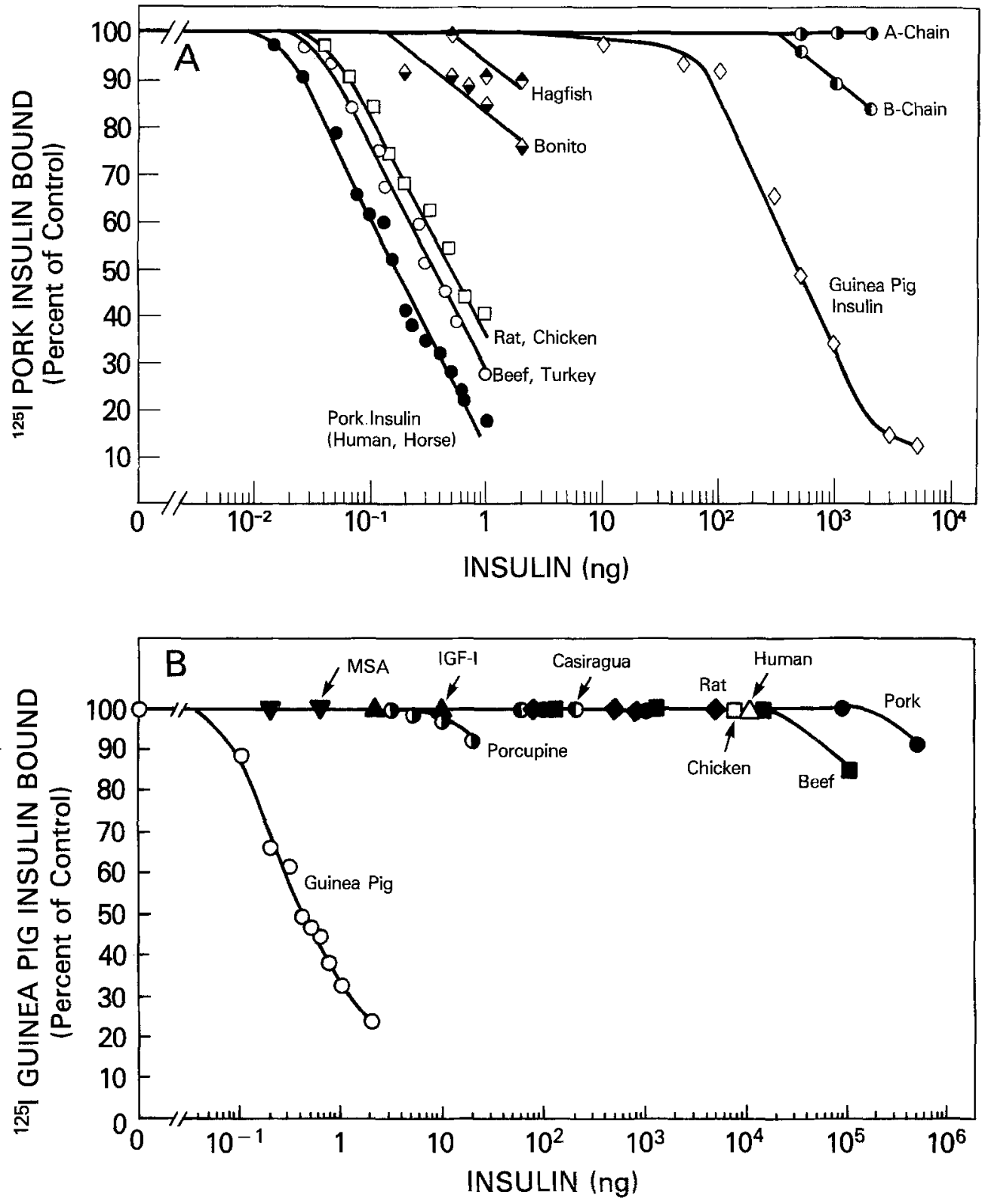

Fig. 1. A Pork insulin radioimmunoassay using antibody 619. ${ }^{125} \mathrm{I}$-porcine insulin bound to antibody 619 is plotted as a function of the concentration of unlabelled hormone. In the absence of added unlabelled insulin, $40-50 \%$ of the radioactivity was bound and this has been set as $100 \%$. Note that this antibody binds pork insulin roughly three fold more than rat insulin and 5,000 fold more than guinea pig insulin; avian insulins (chicken and turkey) and the bony fish (bonito) and cyclostome (hagfish) insulins react more than guinea pig insulin; only the isolated pure B-chain and A-chain of pork insulin react less well than guinea pig insulin. B Radioimmunoassay of Guinea pig-type insulin. ${ }^{125} \mathrm{I}$-guinea pig insulin bound to specific antibody is plotted as a function of the concentration of unlabelled hormone. In the absence of added unlabelled insulin, $30 \%$ of the radioactivity was bound and this has been set as $100 \%$. Note that the common mammalian insulins (e.g. beef and pork) react less well by at least five orders of magnitude washed with $10 \mathrm{ml}$ of methanol, followed by $20 \mathrm{ml}$ of distilled water. The extracts from step 1 were diluted in five volumes of $1 \mathrm{~mol} / 1$ acetic acid and applied to the Sep-Pak cartridges $[2,5]$ with a constant infusion pump at $1 \mathrm{ml} / \mathrm{min}$. Two cartridges in series were used for each $10 \mathrm{~g}$ wet weight of tissue which corresponded to $\sim 500 \mathrm{ml}$ final volume of diluted extract. Elution was carried out with $0.01 \mathrm{~N} \mathrm{HCl-75 \%}$ ethanol $(1.8 \mathrm{ml})$ at $22^{\circ} \mathrm{C}$; the first $0.6 \mathrm{ml}$ of eluate were discarded and the following $1.2 \mathrm{ml}$ were collected and pooled.

Step 3: Sephadex G-25 filtration. To remove the ethanol from the eluates, $1 \mathrm{ml}$ aliquots of pooled eluates were applied to individual disposable Sephadex G-25 columns (PD-10 Pharmacia, Piscataway, New Jersey) pre-washed with $0.1 \mathrm{~mol} / 1$ acetic acid $(20 \mathrm{ml})$. After elution with $0.1 \mathrm{~mol} / 1$ acetic acid $(6.5 \mathrm{ml})$, the G-25 eluates corresponding to the void volumes, were pooled, frozen, and lyophilized for step 4.

Step 4: Sephadex G-50 gel filtration. (see procedure 1, step 4). Recoveries: to estimate the recovery of insulin by the two procedures, ${ }^{125} \mathrm{I}$-insulin (Sp.act. $125 \mu \mathrm{Ci} / \mu \mathrm{g}$ ), ${ }^{3} \mathrm{H}$-insulin (Sp. act. $80 \mu \mathrm{Ci} / \mu \mathrm{g}$, gift of Dr. P. Halban, Geneva, Switzerland) and unlabelled porcine insulin $(1 \mu \mathrm{g})$ were added to aliquots of guinea pig liver immediately after homogenization in acid-ethanol and then processed by both proce- dures 1 and $2 .{ }^{3} \mathrm{H}$-radioactivity was corrected for variable quenching in the samples by the use of internal standard (addition of ${ }^{3} \mathrm{H}$-uridine to the samples and recounting) as well as an external standard in the scintillation counter (Tracor Analytic, Mark III Elk Grove Village, Illinois). Final recoveries of unlabelled insulin, as well as ${ }^{125} \mathrm{I}$-and ${ }^{3} \mathrm{H}$ insulin, were obtained by measuring the material in the single peak that eluted in the insulin region after the final Sephadex G-50 gel filtration (step 4).

\section{Radioimmunoassay 'of rat/pork'-type-insulin}

'Rat/pork'-type insulin was determined by a double-antibody radioimmunoassay [6] using ${ }^{125} \mathrm{I}$-porcine insulin as tracer, porcine insulin (Elanco, Indianapolis, Indiana) as the standard unlabelled insulin, guinea pig anti-porcine insulin serum (No.619 from Department of Pharmacology, Indiana University, Indianapolis) as the first antibody and rabbit anti-guinea pig IgG as the second antibody. Radioimmunoassay conditions permitted detection of porcine insulin at $7 \mathrm{pg} /$ assay tube although only results of $>10-15 \mathrm{pg}$ were used; rat insulin is two-to sixfold less reactive than porcine insulin (Fig. 1 A). In this radioimmunoassay, purified guinea pig insulin extracted from guinea pig pancreas (either by c.c.yip, or purchased from Novo Laboratory 
Table 1. Procedure 2: percentage insulin recovery from Sep-Pak extraction

\begin{tabular}{|c|c|c|c|}
\hline Extraction step & $\begin{array}{l}{ }^{125}[]-\text { insulin } \\
179,000 \mathrm{cpm} \\
(\%)\end{array}$ & $\begin{array}{l}{\left[{ }^{3} \mathrm{H}\right] \text {-insulin }} \\
43,000 \mathrm{cpm} \\
(\%)\end{array}$ & $\begin{array}{l}\text { Cold insulin } \\
1 \mu \mathrm{g} \\
(\%)\end{array}$ \\
\hline $\begin{array}{l}\text { Insulin added } \\
\text { after homogenization }\end{array}$ & 100 & 100 & 100 \\
\hline $\begin{array}{l}\text { 1. Centrifugation of } \\
\text { homogenate }\end{array}$ & 64 & 67 & - \\
\hline $\begin{array}{l}\text { 2. Adsorption to and } \\
\text { elution from C-18 } \\
\text { column }\end{array}$ & 48 & 46 & - \\
\hline $\begin{array}{l}\text { 3. G-25 Sephadex; de- } \\
\text { salting and lyophi- } \\
\text { lization }\end{array}$ & 23 & 42 & - \\
\hline $\begin{array}{l}\text { 4. Sephadex G-50 gel } \\
\text { filtration (insulin } \\
\text { peak only) }\end{array}$ & 20 & 28 & 29 \\
\hline
\end{tabular}
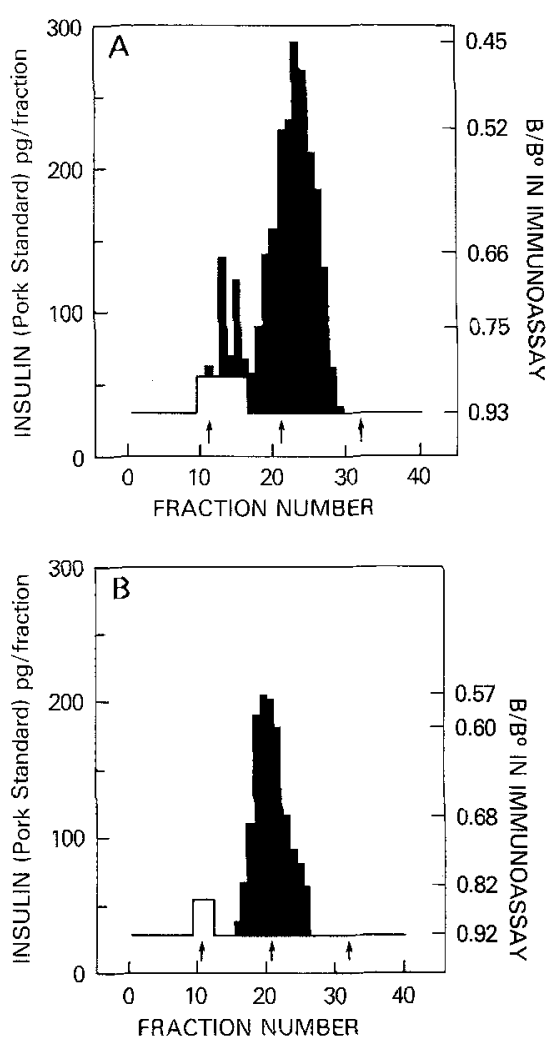

Fig. 2. Sephadex gel filtration of Sep-Pak eluates. Extracts of brain (A) and testes (B) from 20 guinea pigs according to procedure 2 (steps 1-3) were applied to columns of Sephadex $G-50(0.9 \times 50 \mathrm{~cm})$ and eluted in $0.05 \mathrm{~mol} / 1\left(\mathrm{NH}_{4}\right)_{2} \mathrm{CO}_{3}$. The 'rat/pork' type insulin immunoreactivity is plotted as $\mathrm{pg} /$ fraction. The arrows represent the location of markers for the void volume (left), ${ }^{125}$ I-insulin (middle), and ${ }^{125}$ I-iodide (right) that had been run separately. The solid line represents the limits of sensitivity for detection in the immunoassay. Because the samples in the region of the void volume were more difficult to dissolve, the absolute sensitivity was different

Industries, Milton, Connecticut) has only $1 / 5,000$ to $1 / 10,000$ of the reactivity of porcine insulin (Fig. 1A); with fresh extracts of guinea pig pancreas, cross reactivity of guinea pig insulin was $\ll 1 / 100,000$ in this pork insulin assay (Fig. 1 A). Human and rat insulins were a gift of $D$ r. R. E. Chance (Lilly, Indianapolis, Indiana); beef insulin was pur- chased from Elanco; chicken insulin was obtained from the Research Resource Program of NIADDK, (NIH, Bethesda, MD, USA) and multiplication stimulating activity (MSA), the rat counter-part of human IGF-II), was a gift of Dr. M.M. Rechler (NIH, Bethesda).

\section{Radioimmunoassay of guinea pig-type insulin}

Guinea pig insulin and rabbit anti-guinea pig insulin antibody were prepared by c.c.yip. Guinea pig-type insulin was measured by a double antibody radioimmunoassay as described previously [7, 8]; porcine, bovine, human, and rat insulins are virtually non-reactive at concentrations one million times those used for the guinea pig insulin standard curve (Fig. 1 B).

\section{Exclusion of non-specificity in the radioimmunoassay}

To exclude the possibility that substances in the final gel-filtered extracts prepared by procedure 2 interfered in the porcine insulin radioimmunoassay, five experiments were performed: (1) Supernatants from the radioimmunoassay were reacted with trichloroacetic acid (final concentration $5 \%$ ) and the percentage of ${ }^{125}$ I-insulin radioactivity that precipitated was measured. (2) The final G-50 Sephadex purified extracts were incubated with porcine ${ }^{125}$ I-insulin for 3 days in radioimmunoassay buffer. Subsequently they were gel filtered on Sephadex G-50 (fine) and the radioactivity in the eluant fractions was measured. Porcine ${ }^{125} \mathrm{I}$-insulin was incubated with and without extracts under radioimmunoassay conditions. Immediately before addition of second antibody, an excess of anti-insulin (first) antibody was added and the radioactivity which precipitated was measured. (4) The extract was incubated with a high concentration of porcine ${ }^{125}$ I-insulin for 3 days under typical conditions of radioimmunoassay. This material was then diluted and used as tracer in a subsequent pork insulin radioimmunoassay. (5) The purified extracts were tested for reactivity in a human growth hormone radioimmunoassay that utilized the same carrier $\gamma$ globulin and rabbit anti-guinea pig (second) antibody as that used in the porcine insulin assay.

\section{Group studies}

All studies described above were performed by the NIH group. In addition, four other laboratories (Tennessee, South Carolina, Ohio, New York), each performed experiments on guinea pig brain and testis using extraction procedure 2. Twenty guinea pigs (NIH strain), disposable blenders and utensils were shipped directly from the NIH to each investigator. At the completion of the experiments, samples were transferred frozen, ready for assay to the contract radioimmunoassay laboratory (Meloy Laboratories, Springfield, Virginia).

\section{Results}

\section{Insulin recovery from procedure 2}

With procedure 2 (Sep-Pak technique) the final recoveries of the added insulins were $20-30 \%$ (Table 1 ), and there was good correlation among the three insulin preparations. The report of $\gg 75 \%$ recovery by other workers [2,5] applies only for unlabelled and ${ }^{125} \mathrm{I}$-labelled hormone added after the completion of our step 1 or step 2.

With procedure 1 (data not shown), the final recoveries showed poor correlation between the different insulin markers; when the final product was filtered on Sephadex G-50 (step 4), 4\% of ${ }^{125} \mathrm{I}$-insulin, $34 \%$ of ${ }^{3} \mathrm{H}$ insulin and $14 \%$ of the unlabeled insulin were recovered 
in the region of insulin. Much of the ${ }^{125} \mathrm{I}$-insulin, but not ${ }^{3} \mathrm{H}$-insulin, was lost in the precipitate at the time of neutralization (step 3).

\section{Immunoactive 'rat/pork'-type insulin in guinea pig brain and testes.}

Guinea pig brain and testes were extracted and processed by procedure 2 . No insulin-related immunoactivity was detected in eluates assayed at a dilution of 1:10 (data not shown). Ethanol in the eluates was removed by Sephadex G-25 gel filtration and the material concentrated by lyophilization. Following chromatography on Sephadex G-50 fine, a broad peak of 'rat/ pork'-type insulin immunoactivity was recovered in the region appropriate for insulin (Fig. 2). The insulin content of this peak in nine separate experiments ranged from 4 to $60 \mathrm{pg}$ 'rat/pork'-type insulin immunoactivity/g wet weight of tissue (Fig.3).

\section{Exclusion of artifacts in the immunoassay}

Five experiments were performed to exclude the possibility that substances in the gel filtered extract (procedure 2) interfered in the insulin immunoassay. In the first experiment, $94 \%$ of the ${ }^{125} \mathrm{I}$-insulin radioactivity was precipitated by trichloroacetic acid irrespective of whether the tracer had been incubated in the presence or absence of gel filtered extract for 3 days at $4^{\circ} \mathrm{C}$. In the second experiment, almost all of the radioactivity added to the extract was recovered in the region typical of insulin in a profile identical to that seen when tracer

BRAIN

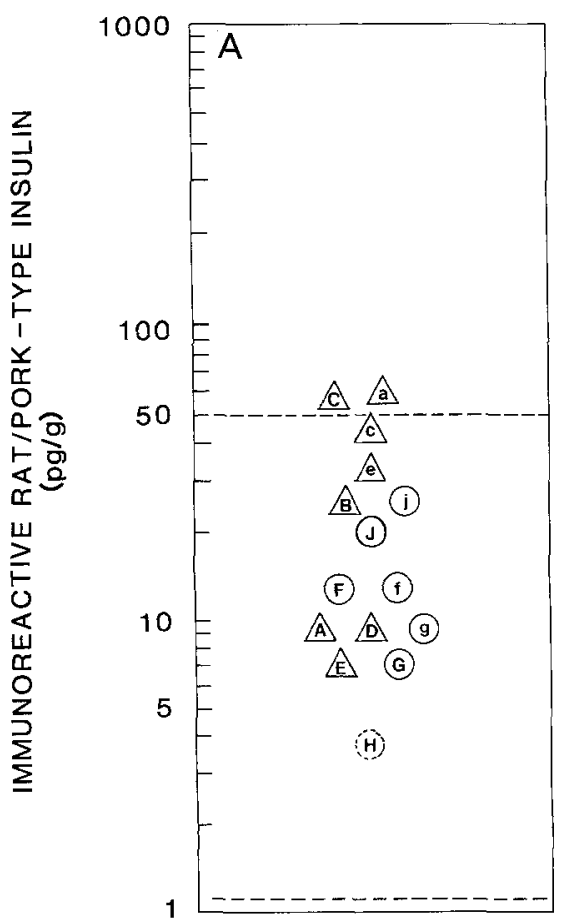

was incubated in the absence of gel filtered tissue extract (Fig. 4A and B). In the third experiment, tracer was incubated with extract, and after 3 days at $4{ }^{\circ} \mathrm{C}$ we added an excess of first antibody (anti-insulin antibody); this antibody precipitated $>90 \%$ of the radioactivity (when second antibody was added) irrespective of whether the ${ }^{125} \mathrm{I}$-insulin radioactivity was incubated in the presence or absence of gel filtered extract. When ${ }^{125}$ I-insulin was incubated for 3 days with the extract and then used (diluted) as a tracer in a subsequent pork insulin radioimmunoassay, results obtained were indistinguishable from results obtained with ${ }^{125}$ I-insulin incubated in the absence of extract. In the fifth experiment, the purified extracts were non-reactive in the human growth hormone radioimmunoassay (see Methods). We concluded that degradation (or subtle alteration of the immunological integrity) of the ${ }^{125}$ I-insulin tracer by the gel filtered extract were excluded in experiments 1-4. Interference in the assay due to binding of the ${ }^{125}$ I-insulin tracer by materials in the extract was excluded in experiment 2, while experiments 3 and 5 showed that the extract did not alter the ability of the second antibody to bind to and precipitate the first antibody in the radioimmunoassay.

Fig. 3 A and B. Brain and testes from 20 guinea pigs were homogenized in acid-ethanol and extracted according to procedure 2 . The results are plotted as rat/pork-type insulin immunoactivity per gram wet weight of tissue. $(\mathbf{A}, \mathbf{B})$ The lower broken horizontal line represents the lower limit of detectability in our assay using pooled, gel filtered tissue extracts. Experiments A-E represent results of separate experiments performed by five individuals in Bethesda and experiments F-J represent studies performed by investigators in the four laboratories outside of Bethesda; none of these four laboratories performed insulin immunoassays, but they used the same protocol to prepare the extracts and sent the samples to a contract laboratory for immunoassays of insulin. Lower case letters indicate results obtained with extracts after step 3. Upper case letters indicate results obtained with extracts after step 4. The immunoactivity in solvent and buffer blanks, carried through the entire procedure from the homogenization (step 1) or from the G-25 Sephadex (step 3), were unmeasurable or low, e.g. $1 \mathrm{pg} / \mathrm{g}$ for brain and $2 \mathrm{pg} / \mathrm{g}$ for testis. The only exception is the brain sample $\mathbf{H}$, where the extract labelled blank gave a value of approximately $3.5 \mathrm{pg} / \mathrm{g}$, and that labelled experimental gave results $\ll 1 \mathrm{pg} / \mathrm{g}$; we suspect that the two extracts were reversed and have used the broken symbol to designate the uncertainty 

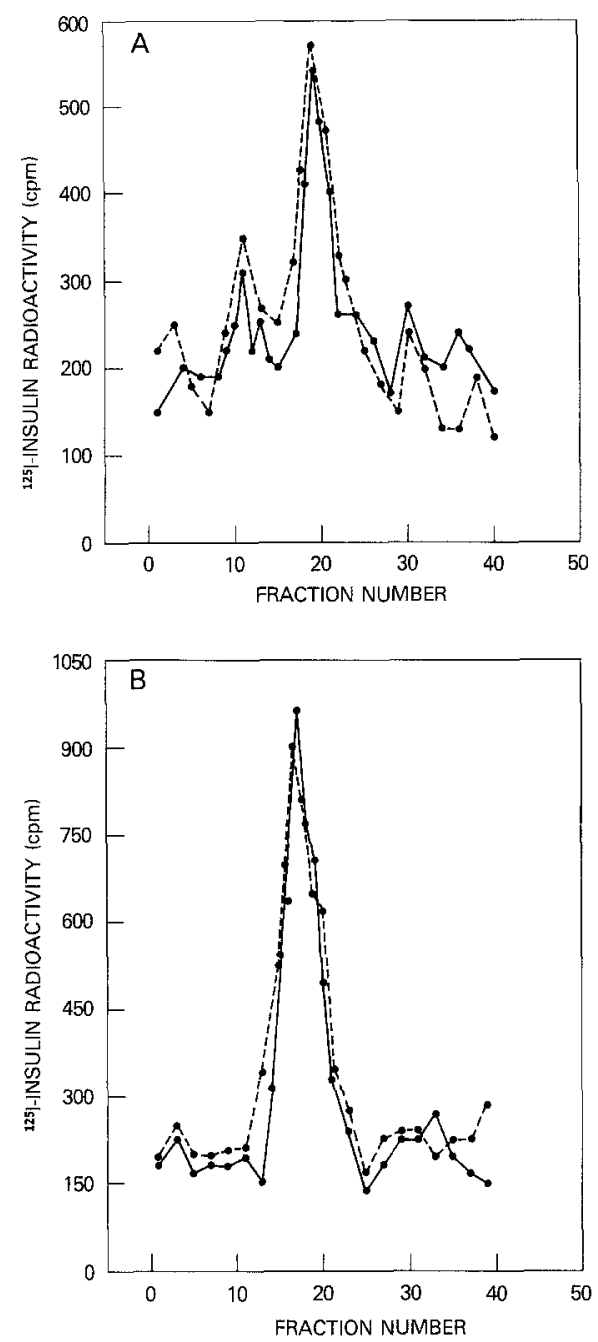

Fig. $4 \mathrm{~A}$ and B. Gel filtration of tracer insulin following incubation with extracts of guinea pig brain and testes. Following Sephadex G-50 gel filtration of extracts of guinea pig brain and testis, the peak fractions containing insulin immunoactivity were pooled and concentrated by lyophilization. Each pooled fraction was incubated for 3 days with tracer insulin, under conditions of the insulin radioimmunoassay. Both ${ }^{125} \mathrm{I}$-porcine insulin incubated with (_- ) and without (o----o) extract were gel filtered separately on a column of Sephadex G-50 (superfine) and eluted with $0.05 \mathrm{~mol} / 1\left(\mathrm{NH}_{4}\right)_{2} \mathrm{CO}_{3}{ }^{125} \mathrm{I}$-insulin content of each eluant fraction was counted and plotted for brain (A) and testes (B)

\section{Exclusion of exogenous contamination}

To exclude exogenous contamination, extra precautions were taken in these experiments including use of brand new utensils wherever possible. In addition, at each step of extraction and purification procedures, blanks run in parallel were routinely assayed and found to be devoid of insulin immunoactivity. Further, the experiments were repeated at other sites at the National Institutes of Health and by several investigators at multiple locations in our laboratory; in each case identical results were obtained (Fig. 3). In addition, four other groups of investi-

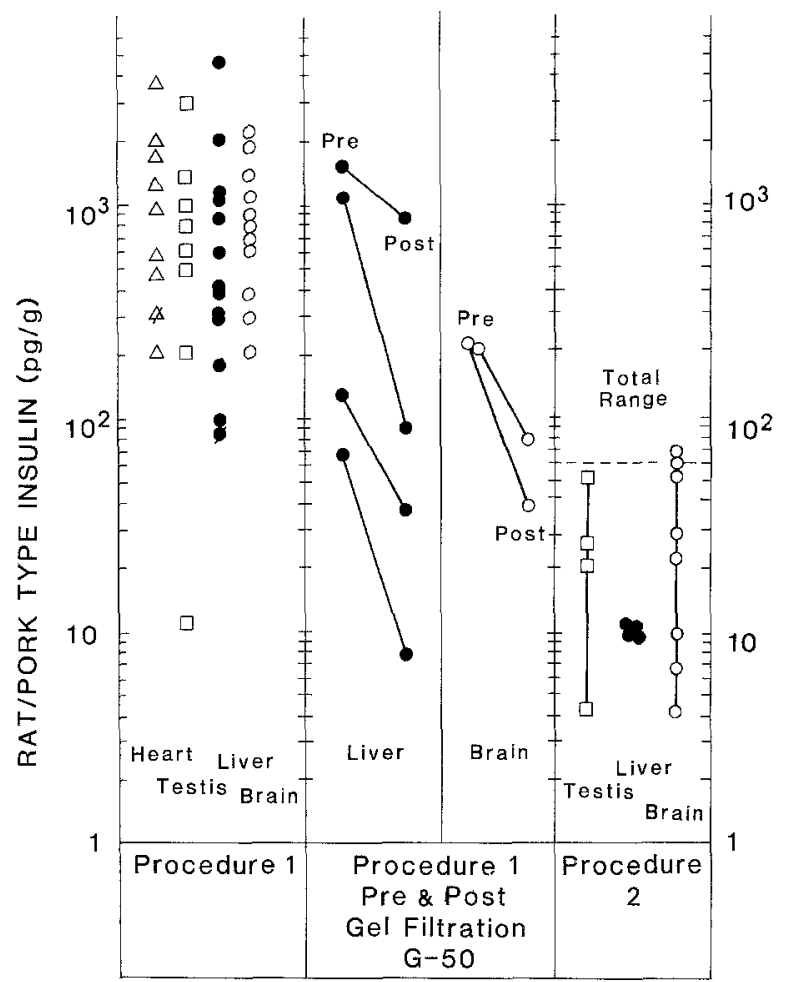

Fig. 5. Comparison of different methods of extraction and purification. 'Rat/pork' type insulin immunoactivity in extracts of guinea pig tissues is expressed as pg equivalents of pork insulin $/ g$ wet weight of tissue. Left panel: tissues were extracted by the classical method, designated procedure 1 (steps 1-3) in Methods. Each point represents an individual experiment. (Means \pm SEM were reported in our preliminary communication [1].) For comparison, results of comparable extracts and assays done by C.C. Yip entirely in Toronto are presented ( $\triangle$ and $\sigma$ ). Centre panel: experiments in which guinea pig liver and brain were extracted by procedure 1 (steps 1-3) are designated pre-gel filtration G-50. Aliquots of these extracts were gel filtered on Sephadex G-50 (step 4), and each effluent fraction was lyophilized, reconstituted, and assayed; values designated post-gel filtration G-50 represent the total insulin immunoactivity in the peak corresponding only to the region of insulin. Right panel: studies with the new SepPak method (procedure 2) are presented for comparison. For liver, individual experiments are presented. Similar data for brain and testes from our laboratory are included (A-E, Fig.3). In comparable studies by others [2], the level of sensitivity was $>50 \mathrm{pg} / \mathrm{g}$ (indicated by ---), which accounts for their failure to detect rat/pork type insulin in Sep-Pak extracts of guinea pig tissues. The decrease in insulin immunoactivity in going from procedure 1 (left panel) to procedure 2 (right panel), observed here for guinea pig tissues is comparable to the $70-90 \%$ decrease obtained by others [10 versus 5] with similar extracts of tissues (procedures 1 and 2) from rabbit (kidney, liver, and brain) and rat (brain); summarized in Figure 17 [9]

gators (Tennessee, South Carolina, Ohio, New York) repeated these experiments using the identical protocol. The results from these investigators were indistinguishable from those obtained in Bethesda (Fig.3). Another independent investigator performed similar experiments and obtained results similar to our own [3].

\section{Comparison with our earlier studies}

In a preliminary study [1] of 'rat/pork'-type insulin immunoactivity in extra pancreatic tissues of the guinea pig, we used extraction procedure 1. In Figure 5, we 
have represented the individual uncorrected data for heart, brain, liver and testes from those preliminary studies. These results were confirmed in Toronto by c. c. yip using extracts of guinea pig heart and liver prepared in one laboratory and immunoassayed in another laboratory elsewhere in Toronto (Fig. 5). Similar results were obtained in a joint experiment by Eng and Rosenzweig $[9$, p. 333] and by an independent investigator in England [3]. All these results, like those in the preliminary studies, were obtained with tissue extracts that had not been gel filtered. In the present study extracts of liver and brain prepared by procedure 1 were tested for insulin immunoactivity prior to and following gel filtration on Sephadex G-50. As shown in Figure 5 the immunoactive insulin content in the insulin region following gel filtration gave lower levels than the insulin immunoactivity measured prior to gel filtration. Possible reasons for these marked changes include removal of interfering substances by the chromatographic step, repeated lyophilization of samples to dryness or alternatively, insulin adsorbing to Sephadex. Recovery experiments using purified ${ }^{125} \mathrm{I}$-insulin and ${ }^{3} \mathrm{H}$-insulin demonstrated significant, though variable losses at the Sephadex G-50 chromatographic step; $33 \%$ loss of ${ }^{3} \mathrm{H}$ insulin in procedure 2 (Table 1 ) and $25 \%$ loss in procedure 1 (data not shown).

Extracts of guinea pig testis and brain prepared by procedure 2 demonstrated levels of immunoactive 'rat/ pork'-type insulin that were $40-50$ fold lower than those obtained using procedure 1 (Fig.5). In addition, levels obtained from liver were quite similar.

\section{Discussion}

In our preliminary study [1], we reported the presence of pork-type insulin immunoactivity in acid ethanol extracts of many extrapancreatic tissues of the guinea pig that migrated on Sephadex G-50 in the region where insulin is known to migrate. This immunoactive insulin peak was biologically active and in addition, the bioactivity was largely though not fully neutralized by an anti-pork insulin antibody. The extracts of extrapancreatic tissues of the guinea pig also contained small amounts of classic guinea pig-type immunoactive insulin $(<$ $1 \mathrm{ng} / \mathrm{g}$ ) which could account for the small amount of biological activity that was not neutralized by anti-porcine insulin antibody. On the other hand, since guinea pig insulin reacts less than 1 in 5,000 as well as pork insulin in our insulin immunoassays, this small amount of guinea pig insulin could not account for the 'rat/ pork'-type insulin immunoactivity detected in the extrapancreatic tissues of the guinea pig. Similarly it is unlikely to account for the 'rat/pork'-type insulin detected in the extrapancreatic tissues in the present study. Additional supportive evidence is the fact that a monoclonalpolyclonal antibody directed towards typical mammal- ian insulins, immunoprecipitated the 'rat/pork'-type insulin in the extracts [9].

Initially we described this extrapancreatic insulin as 'pork-type' [1]. Since it cross-reacts as closely to rat insulin standards (and other typical mammalian insulins) we have renamed it 'rat/pork'-type insulin to indicate our inability to characterize it more accurately.

In the present study, using a different extraction method (procedure 2), we again demonstrated 'rat/ pork'-type insulin immunoactivity in guinea pig extrapancreatic tissues that eluted on G-50 Sephadex (fine) columns in the insulin region. The immunoactivity could not be accounted for by guinea pig insulin in the extracts and numerous experiments were performed to exclude immunoassay artifacts in the gel filtered extract. Replication of the data by four collaborating groups elsewhere in the US provides strong evidence against contamination of the extract by exogenous insulin. Numerous experiments excluded substances in the extracted material that produce artifactual effects in the assay.

In the earlier study [1] we reported levels of insulin immunoactivity in extrapancreatic tissues much higher than those obtained in the present study, a difference most likely explained by the changes in methodology. The results in the preliminary investigation were obtained with extraction procedure 1 , whereas in the present study, the results were compared using both procedures. Furthermore, we demonstrate that significant losses of immunoactive insulin occur at various stages of purification. Similarly Eng and Yalow, with extracts of tissues from rats and rabbits, reported lower levels using Sep-Pak cartridges compared with their earlier extraction procedure $[5,10]$. Using, Sep-Pak cartridges, they reported that they were unable to detect rat/porktype insulin immunoactivity in extrapancreatic tissues of the guinea pig, or more precisely, that the insulin concentration was at or below $50 \mathrm{pg} / \mathrm{g}$ using the same antiserum 619 as used in this study [9, p.332]. We conclude, however, that their results are not incompatable with our present findings; using Sep-Pak cartridges we recover 4-60 pg of immunoactive 'rat/pork'-type insu$\mathrm{lin} / \mathrm{g}$ of tissue. Having excluded artifacts in the various assays as a cause for our findings, we systematically set out to exclude contamination from exogenous sources. We did not find tissues lacking insulin immunoactivity and therefore used buffers without tissue extracts as controls for each procedure. These blank runs were consistently negative for insulin immunoactivity. The strongest argument against contamination comes from the finding that the four other laboratories were able to reproduce our results using our identical protocol. Final proof that this material is indeed insulin, or some other molecule related to insulin, will require determination of the nucleotide sequence of the gene or its messenger RNA or amino-acid sequence of the protein.

In reviewing these studies (and related investigations with other hormones) we suggested that this gui- 
nea pig insulin might be similar in structure to rat insulin [11]. Subsequently, Chan et al., using cDNA hybridization, were unable to demonstrate the presence of a second pre-proinsulin gene in the guinea pig using a rat insulin probe [12]. Therefore, we now suggest that this guinea pig insulin has a structure that differs significantly, yielding a corresponding nucleotide sequence that fails to hybridize with the rat probe, yet similar enough in structure to be recognized by anti-insulin antibodies and by insulin receptors.

However, in favour of the possibility of extrapancreatic tissue production of insulin are the findings of extrapancreatic insulin gene expression in the rat [13], as well as the demonstration of proinsulin in insulin-related immunoactive material in rat and mouse brain cultures [14]. Furthermore, Budd et al. [16] and Lee et al. [17] have demonstrated mRNA in pituitaries, brain and other extrapancreatic tissues using insulin-specific probes.

Acknowledgments. We thank V. Katz for her excellent secretarial assistance.

\section{References}

1. Rosenzweig JL, Lesniak MA, Samuels BE, Yip CC, Zimmerman AE, Roth J (1980) Insulin in the extrapancreatic tissues of guinea pigs differs markedly from the insulin in their pancreas and plasma. Trans Assoc Am Physicians 93: 263-278

2. Eng J, Yalow RS (1982) Absence of pork-like insulin in guinea pig tissues. Proc Natl Acad Sci USA 79: 2683-2685

3. Stevenson RW (1983) Further evidence for non-pancreatic insulin immunoreactivity in guinea pig brain. Horm Metab Res 15: $526-528$

4. Havrankova J, Roth J, Brownstein MJ (1979) Concentrations of insulin and of insulin receptors in the brain are independent of peripheral insulin levels. J Clin Invest 64: 636-642

5. Eng J, Yalow RS (1981) Evidence against extrapancreatic insulin synthesis. Proc Natl Acad Sci USA 78: 4576-4578
6. LeRoith D, Shiloach J, Roth J, Lesniak MA (1980) Evolutionary origins of vertebrate hormones; substances similar to mammalian insulins are native to unicellular eukaryotes. Proc Natl Acad Sci 77: 6184-6188

7. Zimmerman AE, Yip CC (1974) Guinea pig insulin I: purification and physical properties. J Biol Chem 249: 4021-4025

8. Zimmerman AE, Moule ML, Yip CC (1974) Guinea pig insulin II: biological activity. J Biol Chem 249: 4026-4030

9. LeRoith D, Hendricks SA, Lesniak MA, Rishi S, Becker KL, Havrankova J, Rosenzweig J, Brownstein MJ, Roth J (1983) Insulin and other extrapancreatic tissues of vertebrates and non-vertebrates. In: Szabo AJ (ed) Advances in metabolic disorders: CNS regulation of carohydrate metabolism, Vol.10. Academic Press, New York, pp. 304-340

10. Eng J, Yalow RS (1980) Insulin recoverable from tissues. Diabetes 29: $105-109$

11. Rosenzweig JL, LeRoith D, Lesniak MA, MacIntyre I, Sawyer WH, Roth J (1983) Two distinct insulins in the guinea pig: the broad relevance of these findings to evolution of peptide hormones. Fed Proc 42: 2608-2614

12. Chan SJ, Episkopov V, Zeitlin S, Karathanasis SD, Mackrell A, Steiner DF, Efstratiadis A (1984) Proc Natl Acad Sci 81: 5046-5050

13. Muglia L, Locker J (1984) Extrapancreatic insulin gene expression in the fetal rat. Proc Natl Acad Sci 81: 3635-3639

14. Birch NP, Christie DL, Renwick AGC (1984) Proinsulin-like material in mouse fetal brain cell cultures. FEBS Lett 168:299-302

15. Birch NP, Christie DL, Renwick AGC (1984) Immunoreactive insulin from mouse brain cells in culture and whole rat brain. Biochem J 218: 19-27

16. Budd GC, Pansky B, Cordell B (1983) Insulin or insulin-like peptides in the pituitary gland. J Cell Biol 97: 404A

17. Lee CH, Lin BC, Costa E, Chuang DM (1984) Detection of mRNA species in the brain and other tissues of rat which hybridize with proinsulin gene. Fed Proc 43: 2219 (Abstract)

Received: 17 July 1984

and in revised form: 18 February 1985

Dr. D. LeRoith

Diabetes Branch

National Institutes of Arthritis

Diabetes, Digestive and Kidney Diseases

Building 10, Room 8S-243

National Institutes of Health

Bethesda, MD 20205, USA 